\title{
The Existance of Shared Space with the Container of Character Application Among Low Income Users
}

\author{
Ratna Darmiwati ${ }^{1}$, Happy Ratna Sumartinah ${ }^{2}$ \\ ${ }^{1}$ Department of Architecture, Darma Cendika Catholic University, Surabaya, Indonesia \\ ${ }^{2}$ Department of Architecture, Institute of Technology Sepuluh Nopember ITS, Surabaya, Indonesia
}

Email address:

ratnadarmiwati@gmail.com (R. Darmiwati), happyratna@yahoo.com (H. R. Sumartinah)

\section{To cite this article:}

Ratna Darmiwati, Happy Ratna Sumartinah. The Existance of Shared Space with the Container of Character Application Among Low Income Users. International Journal of Literature and Arts. Vol. 3, No. 4, 2015, pp. 49-53. doi: 10.11648/j.ijla.20150304.13

\begin{abstract}
Humans are social beings, who tend to live together in groups. For low-income people category in the society, togetherness strongly influences the members' way of life. The limited socio-economic factors among the low-income circles, leads to the emergence of settlements and slums that are not orderly. This is due to the various activities these settlements serve to fulfill, such as a togetherness socialization, centers of economic activities, non-formal education, among others. The shared space acts as a container where these various activities take place. Thus, it must be met with the low-income bracket standard so that it can be utilized effectively, in return, making it easier to regulate the placement, while at the same time reducing the disorderliness and untidiness in the settlement as well as the environment. The assessment of the existence of shared space in residential environments, among others is to help ensure that: The existence of shared space, can be accepted by the inhabitants of low-income residents; the shared spaces serve the functions that residents daily activities can take place regularly and fulfill the desire of residents; the existence of shared space is right, and the activities take place comfortably ,safely, orderly and without interfering with privacy of others; the existence of shared spaces meet the terms of architecture that meet environment standards, where noise, ambient temperature, humidity, and odors can be controlled, and infrastructure organized.
\end{abstract}

Keywords: Togetherness, Shared Space, Low Income Society

\section{Introduction}

Human beings need a 'container' to perform various activities, one of which is the residential environment. A settlement is defined as a place, space or area, which residents live together forming a group, thereby the group uses the existing environment to sustain themselves, establish and develop a common life, definition by Lang (1987). ${ }^{6}$

Another definition by Haryadi and Setiawan, (1995), "elaborates a settlement as a residential or a group of houses with all elements as well as activities related to the settlements that exist in the environment". The settlement is one of the basic human needs for carrying out activities, in this case, people need shelter to protect themselves from natural conditions that sometimes may be erratic place. ${ }^{4}$

Rapoport in, (2005), stated that "There is a strong correlation between human behavior, culture and the environment in enhancing the quality of life." Selection of a residence as a dwelling place by the user community, does not always depends on the condition of existing homes alone, but rather on the availability of complete facilities there in accordance with the character and social behavior of the residential user, as well as accessibility to the location that allows it to flourish". ${ }^{11}$

Processing the various notions mentioned above concludes that; a house is a building which serves as a residence or dwelling place, and provides security and comfort to its users as they carrying out internal activities within a family; while a housing is a residential neighborhood that serves as a container for the movement sand interactions of the characters among the user community, and a settlement is a housing with all the amenities and activities that take place according to the character of the user.

A settlement acts as a unified residential group and its environment, for the low-income people, where the inhabitants live in togetherness. Influenced by the character of the settlement's behavior, the existence of shared space as a communal place for residents needs to be adjusted based on 
the interests of the residents, so that it can be used optimally.

The settlements in big cities of Indonesia, reflect the imbalance of development compared to their surrounding areas, this condition makes the citya destination for residents of the lower income category, who are less successful in their home regions. In addition, the local governments in the local areas are not optimal in enhancing the development of their regions making the exodus of their citizensless restrained.

Clustering in groups and togetherness, that a character of low-income people which is common life in the village get incorporated to their life in the city. However, the clusters gradually expand into slums and damage the open space of the city.

According to Silas, (1990), "Job seekers above, still live their life style and characteristics, their cultural roots, even the traditional economic roots, which oftenly cannot be simply dismantled by the penetration of metropolitan urban force".

The communal lifestyle is also exhibited in the living conditions of these circles, because there are those of similar background lived, resulting to the houses being crowded, dirty and unhealthy, that one shelter can be lived more than one family.

A countrified lifestyle that is inherent in the lower classes can not be easily eradicated from among them, even though the location of residence is moved to a location that is in better condition than the original. Therefore, habits which characterize the actual residents must be anticipated and then applied to the new place so that residents can adapt easily, because the residence is a determinant of there's identical occupants and the environment.

\section{Research Objective}

The communal lifestyle that characterizes the behavior of low-income society actually has positive value which needs to be developed, including in the setting up low-expense residences for the low income society who form a significant number of the population. Adjustments to these characters is very important, so that residents can exist and improve life. The steps to achieve the purpose of the study that conduct a survey on shared space through a wide observation of the low-income society. The objective is to identify their character, which is important in order to meet their needs, and to support the improvement to the economy and the existence of family life.

\section{Theory and Research Methods}

Appropriate theory and research methods are required in answering the research objectives, to give the meaning among others, include:

a. Give an idea of the attitude of social behavior and oneness among residents of low-income.

b. Provide an overview of the appropriate place for a shared space that is in suited to the character of lowincome society. c. Provide an overview of shared space that interests the people.

The use of Descriptive -Qualitative- Eksplorative Methods, with the paradigm of low-income people, by linking the behavior of the citizens while emphasizing the character of social interaction in environment among low-income society, is a Grand Theory. This method is considered appropriate to be applied in this study because in addition easy to carry out, credibility and can be met complete data collection.

\section{Result and Discussion (Be Used Basic Theory)}

Humans as social beings, have a tendency to come together, to work together; for the low-income people this condition is a major aspect of their life. Research indicates there is a high demand for people to socialize, to meet the needs of life; meaning the existence of shared space is a necessity. That's why in a residential complex, the providence of a shared space as a communal place for residents should consider the character suitability of low-income people. The existence of space is scattered in several places that are selected based on needs of the residents who are the dominant actors dwelling there.

The existence of shared space in low-income residential, could be natural occurring. The shared space had been designed by the government, which is in accordance to the needs of the residents, thus it is in constant use, while there are not meet the needs of the residents, thus left empty. In these spaces, residents interact in various activities, such as talking, selling grocery items or food among others. This creates a necessity for orderliness for the space to be maximum benefit.

According to Weissman, (1981), stated that:

"In the human interaction with the environment, the ability to socialize comfortably, accessibility and adaptability are important in the utilization of a shared space"; means that a shared space that accordance to the character of the residents that is more likely to be utilized in comparison to one that does not meet these specifications. ${ }^{17}$

These factors are likely to facilitate the occurrence of incidences where people group up in one place, where the space may be limited, because it fits with their characteristic needs, they still in group. This result is noise, crowding, and disorderliness.

The socialization of residents in a place that needs to be suitable, there is a requirement that needs to be achieved. The socialization can be more effective, if the environment needs to complement also. If these condition is met, then the citizens can be adapted and comfortable in inhabiting, as well as comfortable in inhabiting, as well as developing their wellbeing.

The shared spaces that exist naturally created to meet a vaious needs of the residents, to be looked to find out deeply if their existence can accommodate the needs, the daily activities of residents of low-income-people in there as 
idential environment; that means an indication of accurat and successful planning.

The key factors to consider in forming a shared space (location of the shared space, accessibility, the number of users, and the management of use by the community), examined in several studies to assess whether the shared space has met the needs of low-income society among others include, whether:

a. Its existence is in accordance to the needs and the behaviour of the residents, so it can be fully accepted the lower classes.

b. Its presence can make occupants feel comfortable, adaptive and active in meeting or socialization, their day-today needs.

c. The location of the shared space meets the architectural requirements and environment standards (Lang,1987) i.e. noise, room temperature, humidity, and smell as well as good-organized in infrastructure. ${ }^{6}$

d. The shared space is in accordance to the government plans, and the presence does not interfere with other facilities.

e. Syani, (1995), stated that :

"The society is an organization where the people are interconnected, with its culture to achieve a common goal". ${ }^{12}$

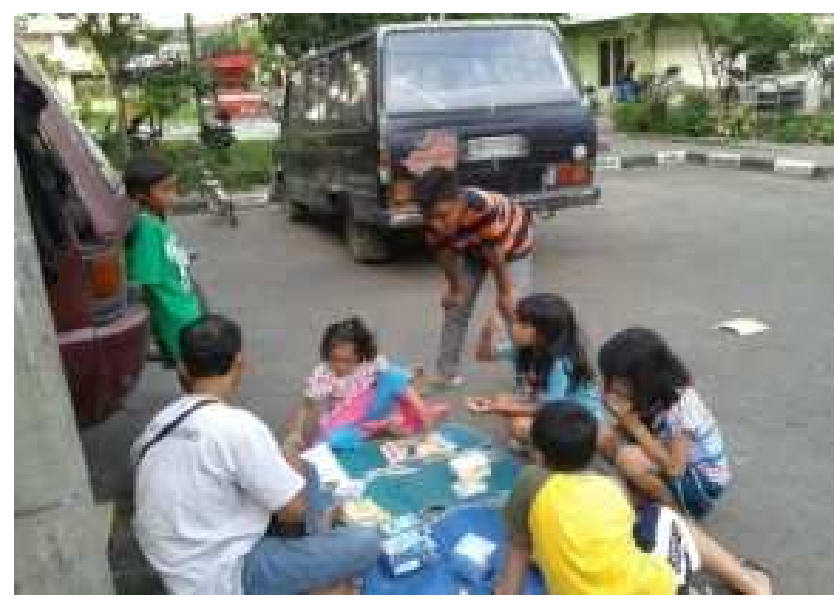

Figure 1. The Uncontrolled Shared Space in Low Income Community

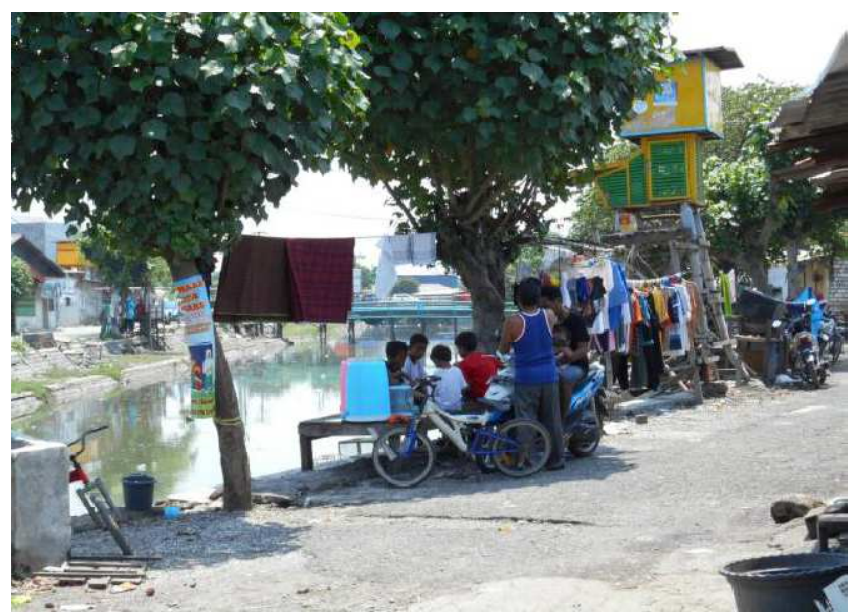

Figure 2. The Hazard Potential of Shared Space on The Street Beside The River
The above statement is further reinforced by Webb, (1990), where stated that:

"In a society, there are three essential elements, namely:

a. The individuals who live in it.

b. The region where individuals interact together.

c. The agreement rules, which control the interrelation between individuals that are inside". ${ }^{16}$

The adaptation of lower classes does not need questioning the new environment, but providence of a "container", a communal space that is in accordance to the characteristics/needs of the occupants for it to be utilized to the maximum by the residents.

The design on the behavior setting, is not always formed by the presence of a permanent space, because for the lowincome earners, their need is a communal space that can provide flexibility in carrying out of their activities.

This condition makes the designing of a communal space free from 'shared space prototypes' that do not fit the pattern of behavior among users of low-income residents.

According to Porteous, (1977), in Lang, (1987), stated that :

"The habits, tradition and past experience of an individual or group will be carried forward to the life in a new environment, so that there will be harmony between the behavior and physical setting; this condition is true also for the low-income societies." 6

The characteristics of low-income-people; togetherness, cooperation, simplicity, and informality, will be applied in formed shared spaces, giving effect to the formation of desired communal space. The existence of shared spaces along side each other interrelates function with the character of the community.

According to Gibson, (1966), in Lang, (1987), stated that:

"Humans have a variety of physical and spiritual needs in principle, which will affect the character's behavior".

The realization of the various needs is hinged on the activities that take place in there's identical environment; because the occupants, know exactly "what forms the need and what is forms the problem". ${ }^{6}$ The potential of the user communities can be developed well, if the shared space that is created can be used to meet the functional needs of residents in the neighborhood. The success of the planning can be achieved only if there is support from the residents, in other words the characteristic of the people need to be accommodated there in.

Statement of Turner. (1972), stated that :

""The most important product of any human activity is, of course, the satisfaction or frustration of the needs". ${ }^{14}$

In essence, humans tend to choose a suitable environment that can satisfy them so as to livewell, after which they prepare for the future of their families and the community at large. If there is a discrepancy between space and behavior that are embodied in it, it causes an undesirable atmosphere, which will have an impact for there's identical environment.

The theory mentioned above, reinforces Maslow's theory, (1987), stated that :

"Man, is the most adaptable creature to the surrounding 
environment, by changing the shape of the environment in accordance with the character of the user". 7

It is clear, that the environment and humans will always mutually off set each other, so that the character of the occupant scan integrate in the environment and minimize the obstacles that may arise, which could harm them, other people and the environment at large.

Rapoport, (1977), stated that: "One major characteristic of cognitive schemata is that they include are as and places never experienced by the rules. The urban areas might be given administrative, residents or planning definitions with corresponding schemata.

The distinction between administrators and other people's schemata, may have major effects on decision making.

People also have schemata of their life space, its territories, barries and paths as related to hierarchy the people and social status". 10

The choice of environment is influenced, among others, by the communal-life space, with regard to the level and social status in the society.

Generally, with the cognitive schema owned by these circles, at the first instance the members will observe their new environment the they will choose it.

Allocation, where the atmosphere issuited to their character and makes them feel comfortable in occupying. Otherwise, if it does not fit, they will try to find a new balance in other location in the same place. The situation goes on until the space can be found by residents that accordance to user's character.

Togetherness is a form of human relationship with each other, between an individual and a group, and between one group with another group; where this relationship takes place on a reciprocal basis, and occurs. In all processes of life, characterized by the behavior of resident occupants" character, which contains the following elements :

a. Human relations.

b. Relationships between people and groups.

c. Inter-group relations.

The shared space is a container that holds a variety of communal activities of occupants both positive and negative; which represent the character of the users to develop the low income society. The shared space, as important component in the study facilitates of variety lowincome residents activities, both physical and non-physical based on the available conditions in environment.

According to Gibberd, (1982), stated that :" The basic element is of course the dwelling. Dwellings, not just houses, are of many kinds and sizes, ranging from flats, to the large houses for large famillies". Associated with each dwelling, are spaces for light and water, and for many other activities where the people can meet. ${ }^{2}$

The essence of a house can be expressed well, if its presence is associated with. Human existence as in habitants; which there is a very deep interrelation together for the indoor communal".

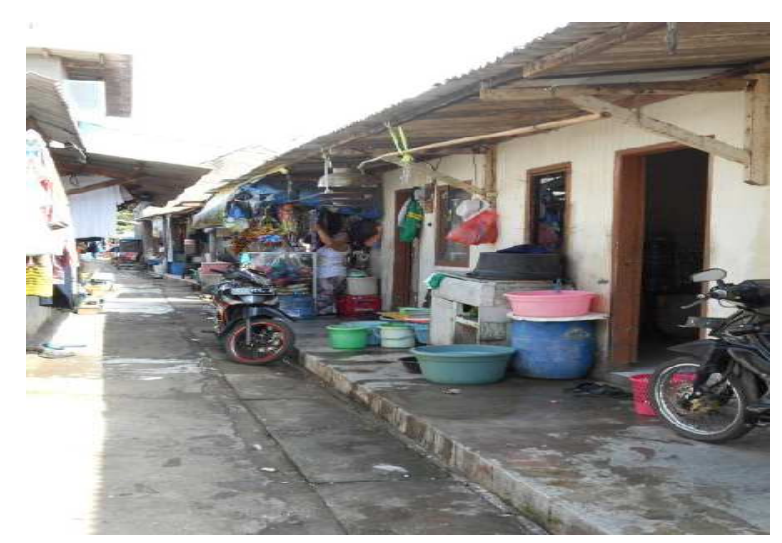

Figure 3. The Uncontrolled of Shared Space in Low Income Community

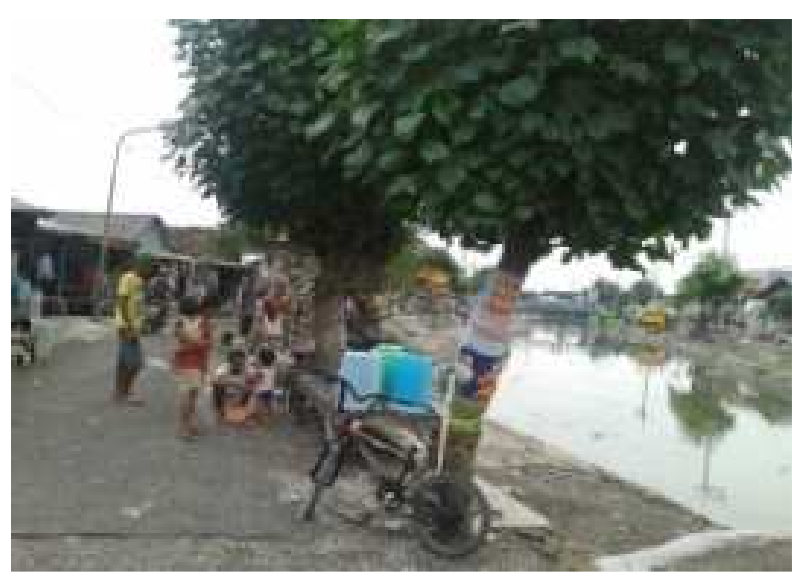

Figure 4. The Hazard Potential of Shared Space on The Street beside The River

Rapoport, (1997), describes the environment as an ecological system having five components :

a. An Individual.

b. A physical environment.

c. A personal environment, including individuals who are important sources of behavior control family, friends, and so on.

d. A supra-personal environment which refers to the environment characteristics.

e. A social environment consisting of social norms and institutions.

"Space is experienced as three dimensional extension of the world which is around us; the intervals, relationships and distances between people, people and things, things, and things. Space is at heart of the built environment". ${ }^{10}$

The togetherness of citizens that takes place in the shared space as the center of activity in the residential environment, affects inter-personal relationships, inter-group relationships, supported by the existing infra-structure there in, where the activities represent the characteristic behavior of the users.

\section{Conclusion}

1. The intent and purpose of the assessment of the existence of shared space in residential environments, among others are to help ensure that : 
a. The existence of shared space, can be accepted by the inhabitants of low-income residents.

b. The shared spaces serve the functions where residents daily activities can take place regularly and fulfill the desire of residents.

c. The existence of shared space is right, and the activities take place comfortably, safely, orderly and without interfering with privacy of others.

d. The existence of shared spaces meet the terms of architecture that meet environment standards (Lang,1987), which noise, ambient temperature, humidity, and odors can be controlled, and infrastructure organized. ${ }^{6}$

2. The color of the character of low-income are togetherness, cooperation, simple, and non-formal; will be applied in a shared space that is formed giving effect to the formation of space desired

3. In essence, humans tend to choose a suitable environment that satisfies them and afterwards they prepare for the future of their families and groups.

4. It is clear, that the environment and humans will always mutually of set each other.

5. The cognitive schema owned by these circles generally, is that at first they will observe the new environment to choose a location, which the atmosphere is matched with the character and comfort in occupying. Otherwise, they will try to find a new balance in the place but in other locations.

6. The shared space is a container that holds a variety of communal activities (positive and negative) for the occupa nts, which is the character of users in.

7. The togetherness of citizens that took place in the shared spaces as the center of activity in there identical environment, affects the relation ships of users.

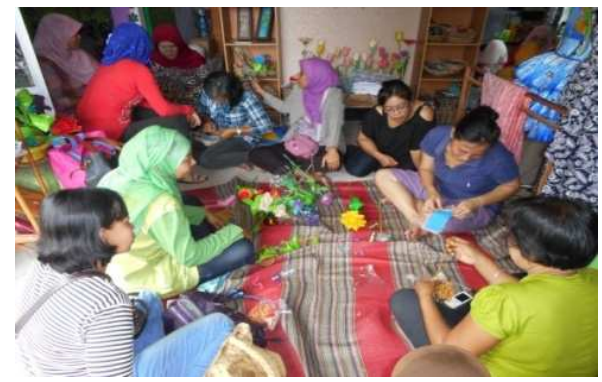

Figure 5. The Good Shared Space in Low Income Community in Kampung Jambangan Surabaya

\section{References}

[1] Altman, and Chemers,, (1984), "Culture and Environment”, Monterey, California, Brooks Cole.

[2] Gibberd, (1982), "The Neighborhood In Town Design", Praeger Publisher, New York.

[3] Glenn, (2004), "Individual Behavior, Culture, and Social Change”, Jurnal of Behavior Analyst Vol 27 No 2.

[4] Haryadi, dan Setiawan , (1995),“Arsitektur Lingkungan dan Perilaku”, Proyek Pengembangan Pusat Studi Dirjen Pendidikan dan Kebudayaan, Yogyakarta.

[5] Jurusan Arsitektur, Fakultas Teknik Sipil dan Perencanaan, Institut Teknologi Sepuluh Nopember,(2013), “International Conference Green Concept in Architecture and Environment.

[6] Lang, (1987), "Creating Architectural Theory, The Role of the Behavioral Sciences in Environmental Design", New York, Van Norstrand Reinhold.

[7] Maslow, (1987), “Psikologi Humanistik”,Kanisius.

[8] Ran Choi, and Geun Lim, (2013), "A Case Study of Cultural Space to Revitalize Local Community”, Jurnal of History and Culture, Vol.1, No.1.

[9] Rapoport, (1969), “House Form and Culture”, Engel wood Clifts, New York, Prentice Hall Inc.

[10] Rapoport, (1977), "Human Aspect of Urban Form", Pergamon Press, New York.

[11] Rapoport, (2005), “ Culture, Architecture, and Design”.

[12] Syani, (1995), "Sosiologi dan Perubahan Masyarakat, Suatu Interpretasi Kearah Realita Sosial”, PT Dunia Pustaka Jaya.

[13] Silas, (1990), "Kampung Surabaya Menuju Metropolitan"

[14] Turner and Fichter , (1972), "Freedom To Build", The Macmillan Company, New York.

[15] Taylor, and Francis, (2012), "The Service cape : The Social Dimensions of Place”, Jouurnal of Marketing Management, Vol.28, No.5.

[16] Webb, (1990), "The City Square”, Thames and Hudson Ltd, London.

[17] Weissman, (1981), "Modelling Environmetal Behavior System, A Brief Nose", Journal of Man Environment Relation,Vol 1 No 2, The Pennsylvania State University. 